\section{MANUFACTURING OF SANDWICH PANELS AND ITS VERIFICATION BY NUMERICAL SIMULATION} MARTIN HARANT ${ }^{1}$, JAN RIHACEK ${ }^{1}$, LIBOR MRNA ${ }^{1,2}$

${ }^{1}$ Brno University of Technology, Faculty of Mechanical Engineering, Institute of Manufacturing Technology, Brno, Czech Republic

${ }^{2}$ Institute of Scientific Instruments of the Czech Academy of Sciences, Brno, Czech Republic

DOI: 10.17973/MMSJ.2021_10_2021087 e-mail: 170977@vutbr.cz

This paper deals with the manufacturing of a parallel hydroformed sandwich panel, which is used as a reinforcement for solar panels. The forming process can cause excessive thinning and cracking. Therefore, PAM-STAMP software is used for the analysis of defects. The outputs of the numerical simulation provide information, such as failure pressure, critical areas or limiting deformations. The comparison of the numerical simulation with the experimentally obtained data is created for the validation of these outputs. The comparative criteria are the failure pressure, the crack zone, and the thickness distribution. Subsequently, the results can be used for a design optimization of the sandwich panel.

KEYWORDS

hydroforming, numerical simulation, PAM-STAMP, DCO1 steel, anisotropy, forming limit diagrams

\section{INTRODUCTION}

Sandwich panels are hybrid systems, which consist of outer layers and acore. The outer layers are made of metallic materials, non-metallic materials, or theirs combinations. The core should be made of lightweight and high-strength materials or structures. Excellent mechanical properties and light weight predetermine sandwich panels for the usage in the aircraft industry, architecture, or military industry. The production of sandwich panels frequently includes unconventional manufacturing processes due to the complex shapes of the parts. The most common processes are forming technologies using flexible tools, such as hydroforming or rubber forming. Sheet metal forming processes can lead to blank thinning or defects formation. They can be analysed and eliminated using a numerical simulation. [Altan 2012], [Campbell 2010]

The manufacturing of the hydroformed sandwich panel is solved within the research project at the Brno University of Technology. The outer layers of the part are made of DC01 steel. The base sheet is $1.5 \mathrm{~mm}$ thick, and the formed sheet is $0.5 \mathrm{~mm}$ thick. The final shape and basic dimensions are shown in Fig. 1.

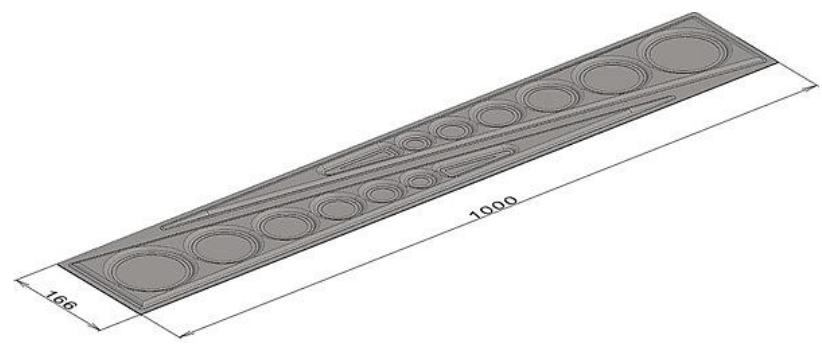

Figure 1: Hydroformed sandwich panel [Harant 2019]

\section{MANUFACTURING TECHNOLOGY}

Hydroforming is a manufacturing technology which allows shaping of materials with pressurized liquid. It is possible to form complex shaped parts thanks to a uniform deformation caused by applied liquid pressure. This process also provides an increase of shape as well as dimensional accuracy, and the possibility of thickness reduction. In this research, the parallel hydroforming process (Fig. 2) was selected for the manufacturing of the sandwich panel. [Liu 2012]

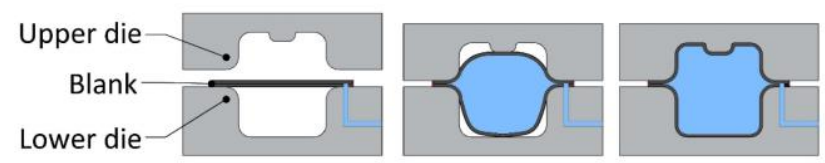

Figure 2: Principle of parallel hydroforming [Liu 2012]

The blank for the technology consists of two sheets which are welded together. The process consists of two steps. Firstly, the blank is freely deformed in a die cavity. The second phase is the calibration and begins with a blank-tool contact. It is important to increase the liquid pressure in this phase. The pressure value for hydroforming processes depends on the blank material and the final shape of the part. [Hein 1999]

Before the actual hydroforming of the sandwich panel, it is important to perform several operations, summarized in the following manufacturing process:

1. manufacturing of the sheets by laser cutting (dimensions of the base sheet and formed sheet are $1.5 \times 166 \times 1000 \mathrm{~mm}$ and $0.5 \times 166 \times 1000 \mathrm{~mm}$ )

2. laser cutting of the shape elements on the formed sheet (radius of the triangle elements is $5 \mathrm{~mm}$ ),

3. thermal friction drilling (Flowdrill) of the liquid inflow on the base sheet (Fig. 3a),

4. keyhole laser welding of the sheets along the shape elements and peripheral edges of the blank (Fig. 3b),

5. parallel hydroforming of the blank.

a)

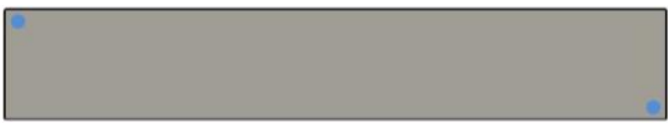

Liquid inflow

b)

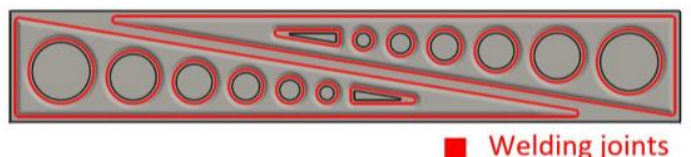

Figure 3: Modifications of the blank before hydroforming a) position of the liquid inflow, b) position of the welding joints

The essential part of the hydroforming device (Fig. 4) is the forming die with the negative shape of the part. After the blank is placed the backplate is situated. The next step is to put down the front plate and to fix the hydroforming device with the connecting screws. The liquid inflow is located in the backplate and the front plate.

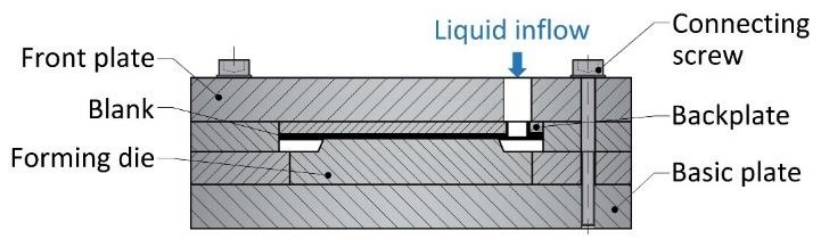

Figure 4: Cross-section of the hydroforming device

Pressurized liquid for the hydroforming is provided by a hydraulic pump. The hydroforming device is clamped between plates of a hydraulic press (Fig. 5), since the high liquid pressure could cause its deformation. 


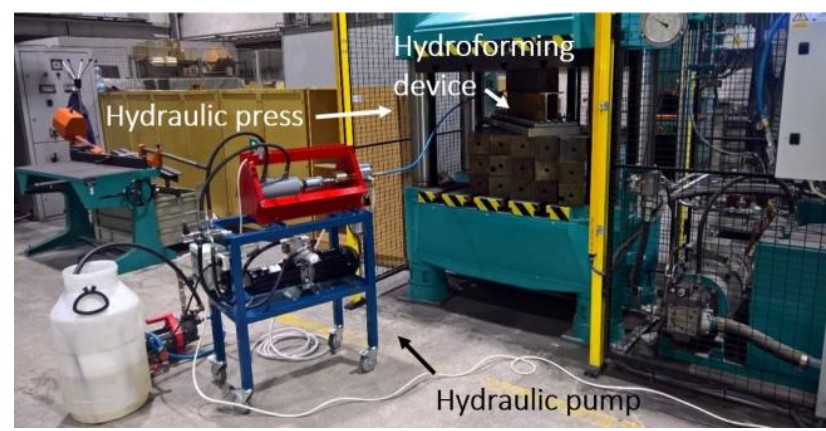

Figure 5: Experimental setup for parallel hydroforming of the part [Harant 2019]

\section{NUMERICAL SIMULATION}

The numerical simulation was developed for the analysis of critical deformations and defects, which can be part of the current manufacturing process. It was performed in the software PAM-STAMP, based on the finite element method.

\subsection{Material model}

Material model is one of the aspects with the highest impact on the accuracy of a numerical simulation. Therefore, it is important that the material model corresponds to the properties of a real material under loading (quasistatic or dynamic). [Buchar 2000] In this case, the forming process is quasistatic. Accordingly, the material model of the DC01 steel was created by the quasistatic tensile test. The mechanical properties were evaluated for 5 specimens with the same orientation as the rolling direction of the sheet. The averaged data of the mechanical properties obtained from the tensile test are summarized in Tab. 1.

\begin{tabular}{|l|l|l||l|}
\hline Yield stress & $\mathrm{R}_{\mathrm{p} 0.2}$ & {$[\mathrm{MPa}]$} & 245 \\
\hline Ultimate stress & $\mathrm{R}_{\mathrm{m}}$ & {$[\mathrm{MPa}]$} & 359 \\
\hline Ductility & $\mathrm{A}_{100}$ & {$[\%]$} & 34.5 \\
\hline
\end{tabular}

Table 1: Mechanical properties of DC01 steel

The measured values were transformed to the true stress-strain curve shown in Fig. 6.

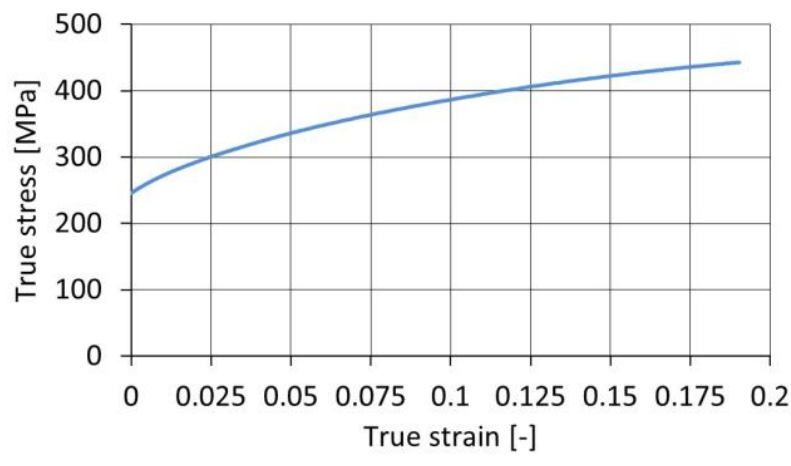

Figure 6: Stress-strain curve of DC01 steel

Metal sheets have a significant anisotropy of mechanical properties. Consequently, it is necessary to include the anisotropic effect in the material model. The experiment was performed on 15 specimens with different orientation relative to the rolling direction $\left(0^{\circ}, 45^{\circ}, 90^{\circ}\right)$ and for $20 \%$ of the plastic strain.

The normal anisotropy coefficient (Lankford parameter) is defined by the following relation:

$r_{\alpha}=\frac{\varphi_{\mathrm{b}}}{\varphi_{\mathrm{s}}}=\frac{\ln \frac{\mathrm{b}_{0}}{\mathrm{~b}_{1}}}{\ln \frac{\mathrm{s}_{0}}{\mathrm{~s}_{1}}}$ where $\varphi_{\mathrm{b}}$ is the true strain in the width direction, $\varphi_{\mathrm{s}}$ is the true strain in the thickness direction, $b_{0}$ is the initial width, $b_{1}$ is the final width, $s_{0}$ is the initial thickness, and $s_{1}$ is the final thickness. Another important parameter for the material model of the numerical simulation is the yield stress ratio expressed as follows:

$\sigma_{\alpha}=\frac{\mathrm{R}_{\mathrm{p} 0.2}\left(\alpha^{\circ}\right)}{\mathrm{R}_{\mathrm{p} 0.2}\left(0^{\circ}\right)}$,

where $R_{p 0.2}\left(\alpha^{\circ}\right)$ is the yield stress corresponding to the direction inclined at the $\alpha$ angle relative to the rolling direction and $R_{p 0.2}\left(0^{\circ}\right)$ is the yield stress in the rolling direction. [Banabic 2010] In Tab. 2 is shown a summary of the calculated anisotropic coefficients.

\begin{tabular}{|l|l|l||l|l|l|}
\hline \multicolumn{2}{|l||}{} & $0^{\circ}$ & $45^{\circ}$ & $90^{\circ}$ \\
\hline Normal anisotropy & $r_{\alpha}$ & {$[-]$} & 1.651 & 1.295 & 1.883 \\
\hline Yield stress ratio & $\sigma_{\alpha}$ & {$[-]$} & 1.000 & 1.034 & 1.022 \\
\hline
\end{tabular}

Table 2: Coefficients of plastic and normal anisotropy

The anisotropy of the mechanical properties is included in the material model by the anisotropic yield stress criterion. ESI MATWIZARD by ESI Group was used for selecting the most appropriate criterion. The input parameters for the comparison are normal anisotropy coefficients, yield stress ratio, etc. Some of the necessary parameters can be approximated by the software. In this case, biaxial yield stress factor is estimated using ESI MAT-WIZARD. Fig. 8 shows the graphically displayed comparison of the anisotropic yield stress criteria.

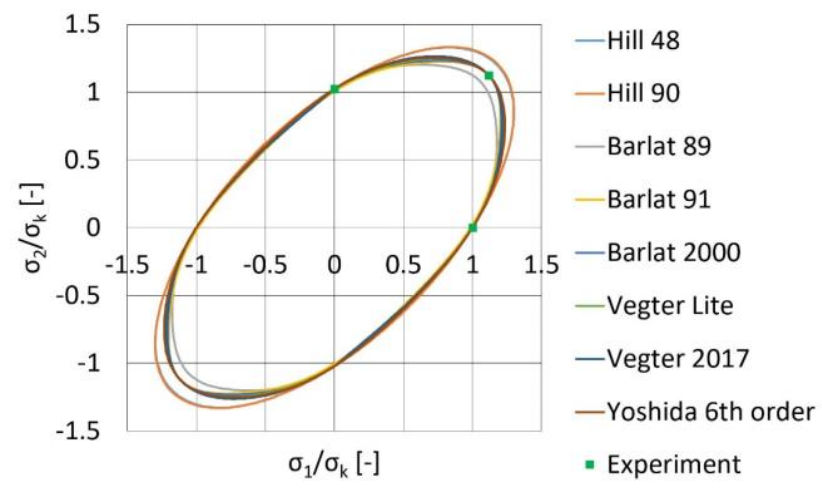

Figure 8: Comparison of the yield strength criteria for DC01 steel [Harant 2019]

The Vegter Lite criterion was selected, based on the comparison of the criteria. The accuracy of this criterion is $99.999 \%$, compared to the experiment (Fig. 9). Another advantage is the small quantity of the input parameters.

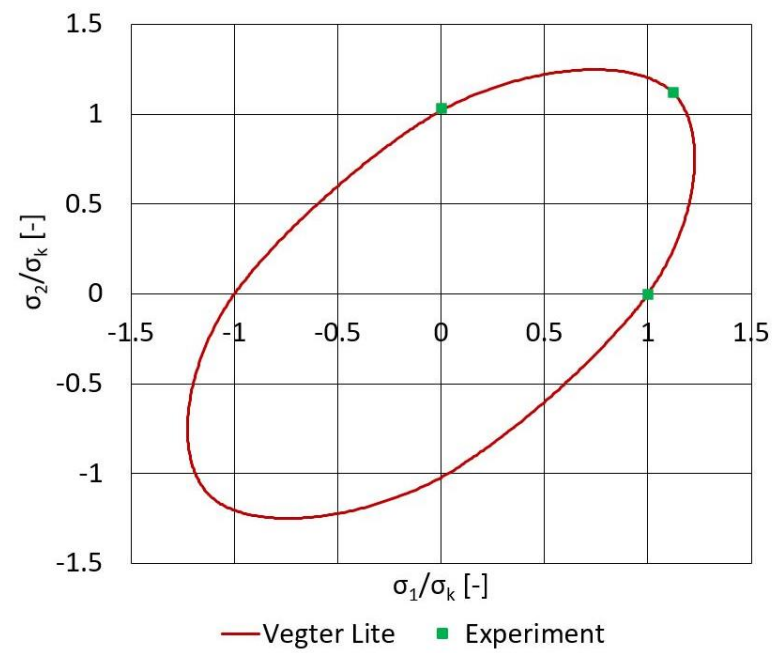

Figure 9: Vegter Lite yield stress criterion [Harant 2019] 
The yield stress criterion is a border between the elastic and plastic behaviour of materials. The elastic properties are defined by Poisson's ratio and Young's modulus. For DC01 steel, these values are $\mu=0.3$ and $E=210000 \mathrm{MPa}$. The true stress-strain curve is entered point by point into the numerical simulation and defines the plastic properties of the material.

\subsection{Geometrical model and boundary conditions}

The geometrical model was created by the software CATIA V5 R20. Parts which do not affect the forming process are not included due to the computational complexity of the solution (Fig. 10).

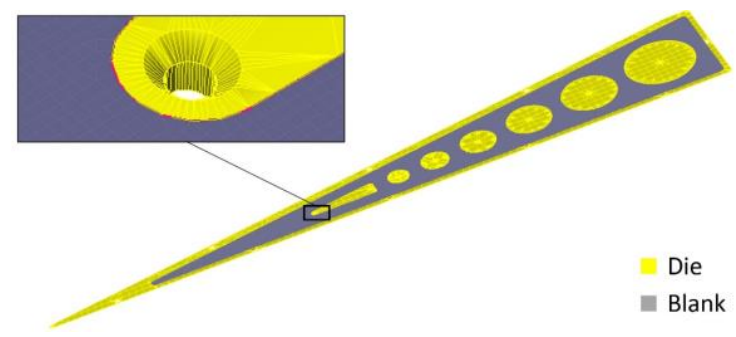

Figure 10: Geometrical model [Harant 2019]

The thickness of the formed sheet is minor in comparison with the other dimensions. The mesh is then created by the shell elements with an edge length of $1 \mathrm{~mm}$. The peripheral edges and the shape elements of the sheet are fixed. The die is defined by its surface with the properties of a rigid body. The pressure value increases linearly from $0 \mathrm{MPa}$ to $8.6 \mathrm{MPa}$. The friction coefficient between the formed sheet and the die is 0.1 .

\subsection{Numerical simulation results}

One of the numerical simulation outputs is the analysis of the critical deformations based on the forming limit diagrams (FLD). The forming limit curve (FLC) is obtained using mathematical description by ESI-MAT WIZARD according on information such as engineering stress-strain curve, material thickness, hardening exponent, etc. Offsetting the FLC by $10 \%$ defines a marginal zone. This region indicates a risk of tearing. Fig. 11 shows the FLD based on strains for the step of the solution when the first critical strains are developed.

a)
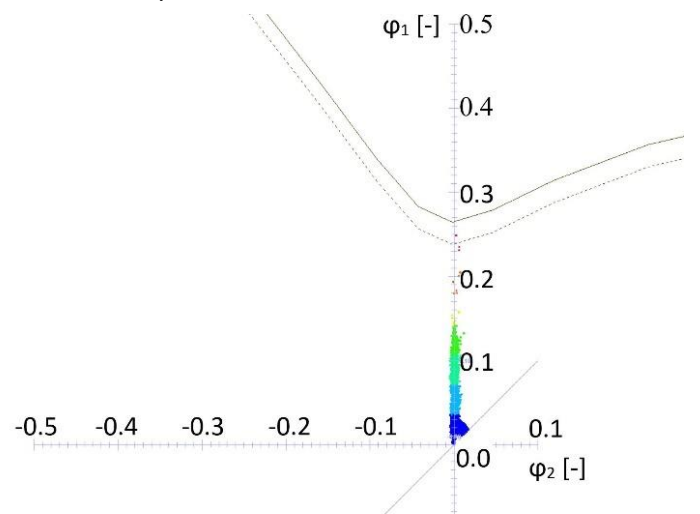

$-0.1$

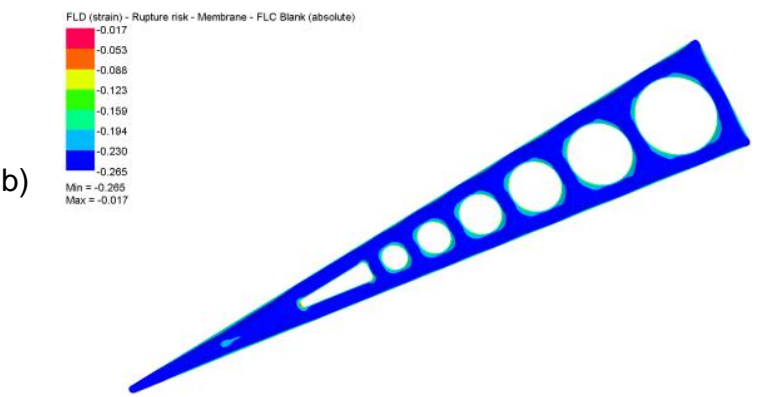

Figure 11: Generated forming limit diagram a) forming limit diagram, b) distribution of FLD points on the part
The thickness distribution is shown in Fig. 12. It is obvious that significant thinning occurred in the area of the peripheral edges and the element shapes of the sheet. The thickness of the critical areas is $0.382 \mathrm{~mm}$. It is a difference of $0.105 \mathrm{~mm}$, compared to the initial thickness.

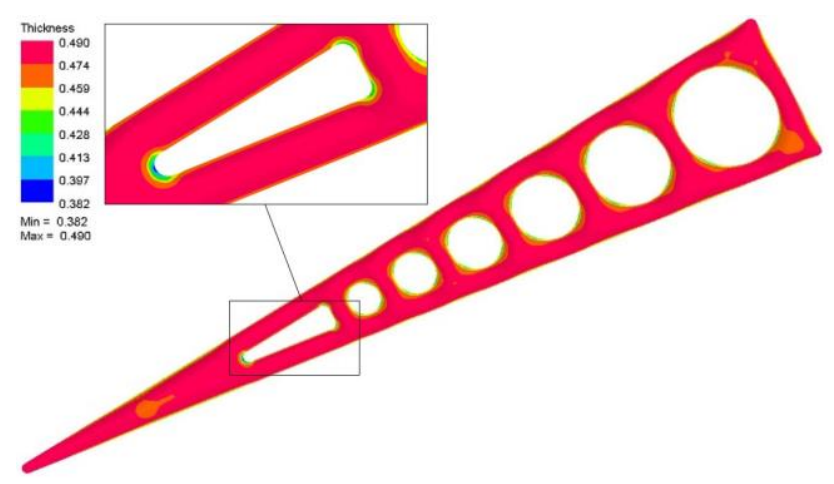

Figure 12: Thickness distribution of the part

\section{VERIFICATION OF NUMERICAL SIMULATION}

There are several ways to verify numerical simulations. The best option is to compare the results with existing experimental data under the same conditions.

In this case, the first indicator is the critical pressure value at which the part failed. The value of $8.6 \mathrm{MPa}$ was determined during the experiment. The numerical simulation results showed the critical pressure of $6.36 \mathrm{MPa}$. The percentage change of $26 \%$ between these values is significant. However, the crack area on the edge of the shape element coincides in both cases, see Fig. 13.

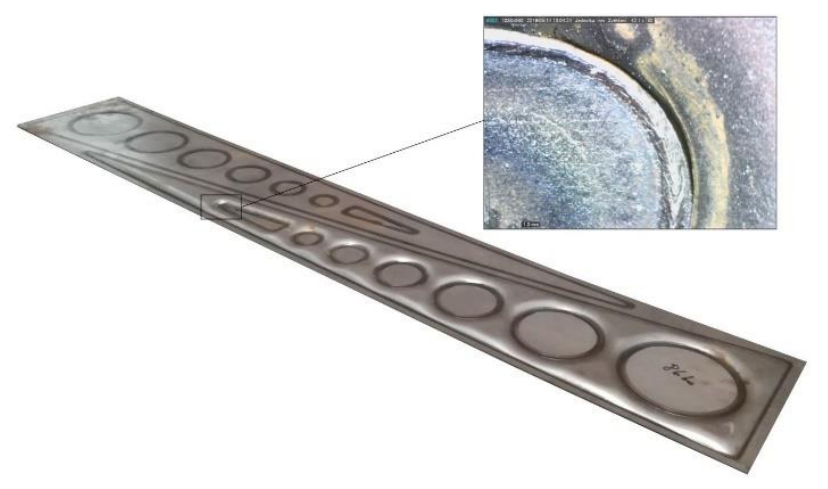

Figure 13: Hydroformed part with crack [Harant 2019]

Another comparison criterion is the thickness distribution after the hydroforming process. Several sections with different stages of deformation were made on the hydroformed part for this purpose (Fig. 14).

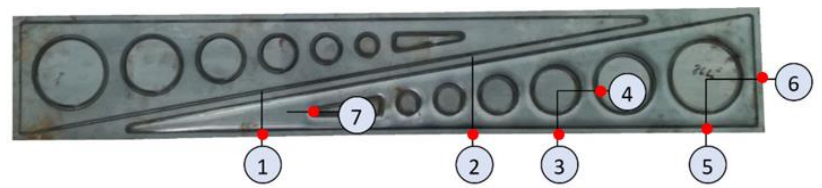

Figure 14: Analysed sections of hydroformed part

The initial thickness of the formed sheet is $0.487 \mathrm{~mm}$. The final thicknesses were measured every $2 \mathrm{~mm}$ with a point micrometer. The start measured points are highlighted with red dots. The calculated data were obtained for the pressure value of $8.6 \mathrm{MPa}$ to make the comparison relevant. Comparison between the measured and the calculated thickness values for the different sections are shown in Fig. 15, 16, 17, 18, 19, 20 and 21. 


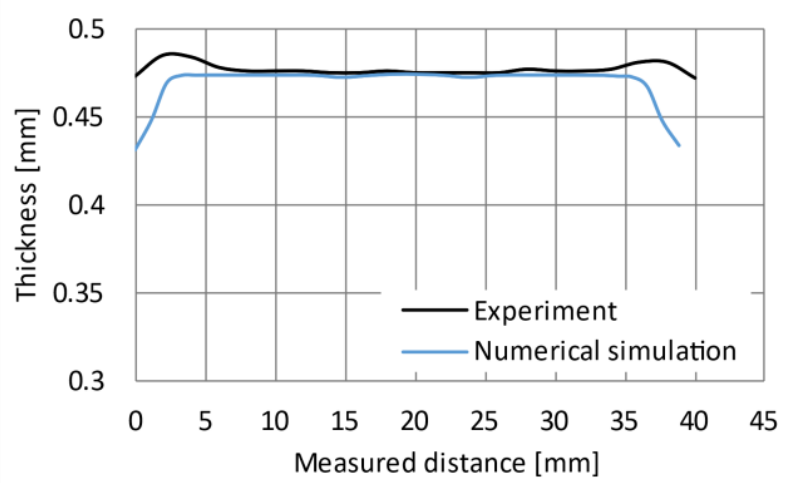

Figure 15: Thickness distribution - section 1

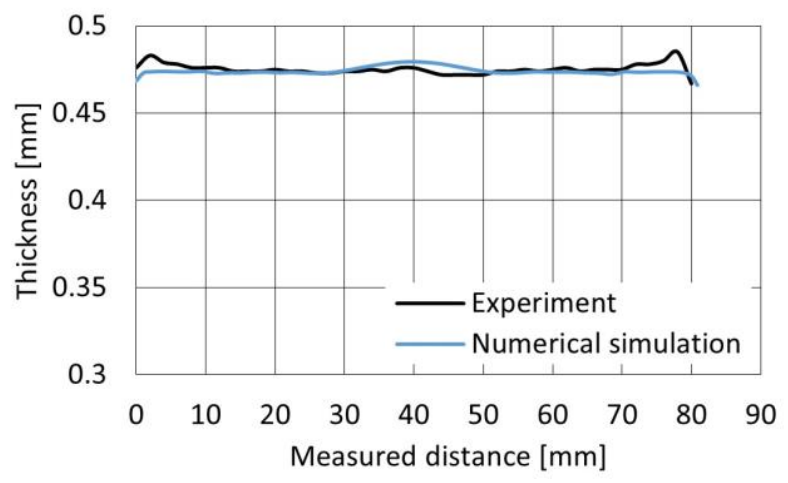

Figure 16: Thickness distribution - section 2

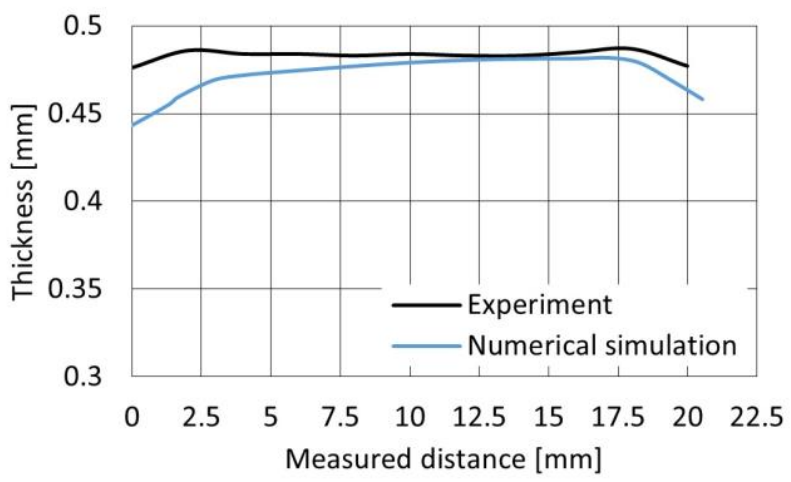

Figure 17: Thickness distribution - section 3

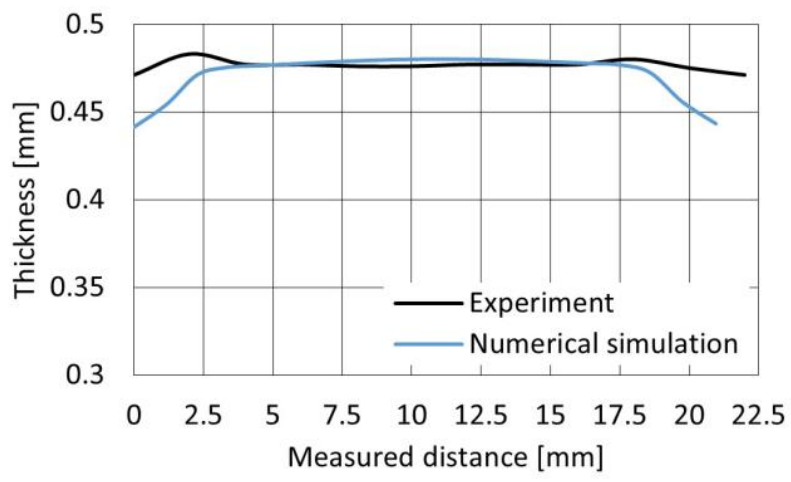

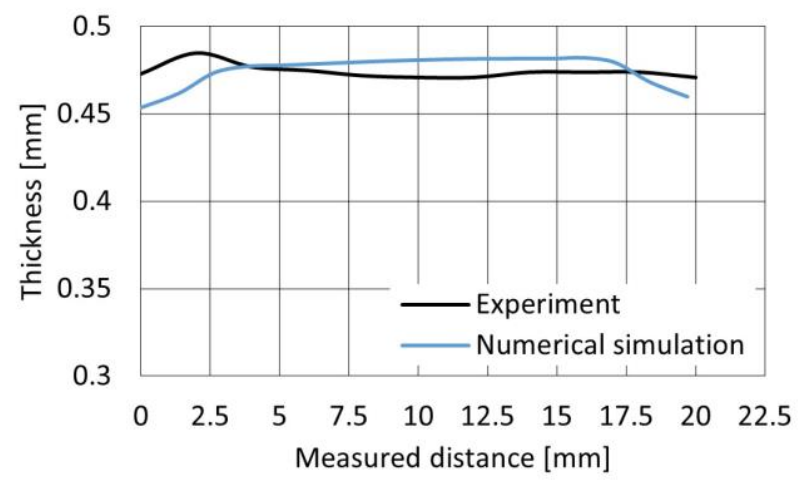

Figure 19: Thickness distribution - section 5

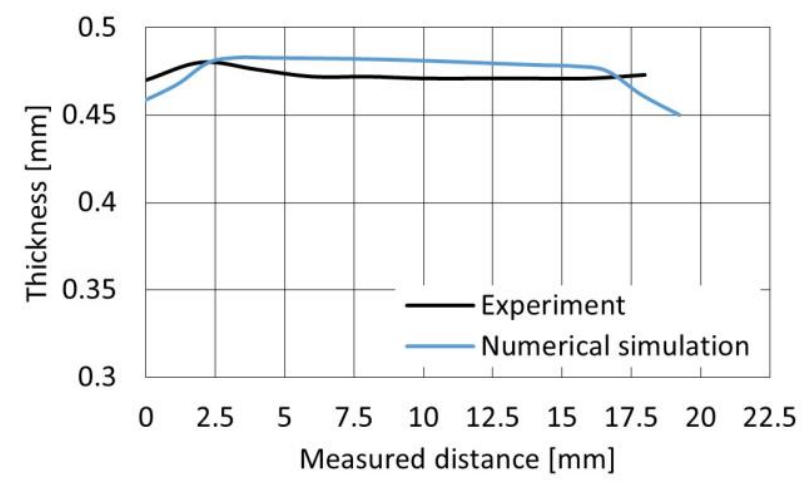

Figure 20: Thickness distribution - section 6

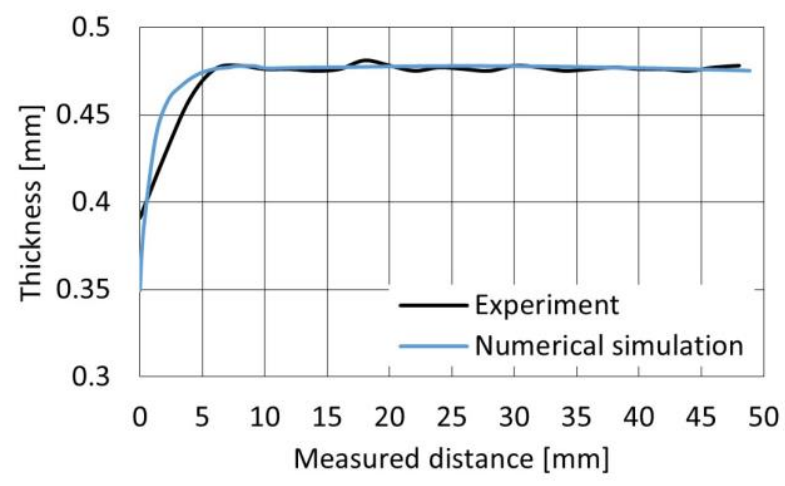

Figure 21: Thickness distribution - section 7

The comparison confirmed that the results of the numerical simulation correspond to the experimental data. The maximum percentage change of $10.7 \%$ was found in section 7 (Fig. 21). However, slightly larger differences are noticed particularly along peripheral parts. The influence of the welding joint, which was not included in the numerical simulation conditions, has an important impact on this fact.

The alternations in material properties (increase in yield stress, ultimate stress, or hardness) are a result of the welding process. The Vickers hardness test was performed to obtain information about the range of alternations on ten measuring points. The initial measuring point was in the middle of the welding joint, see Fig. 22.

Figure 18: Thickness distribution - section 4 


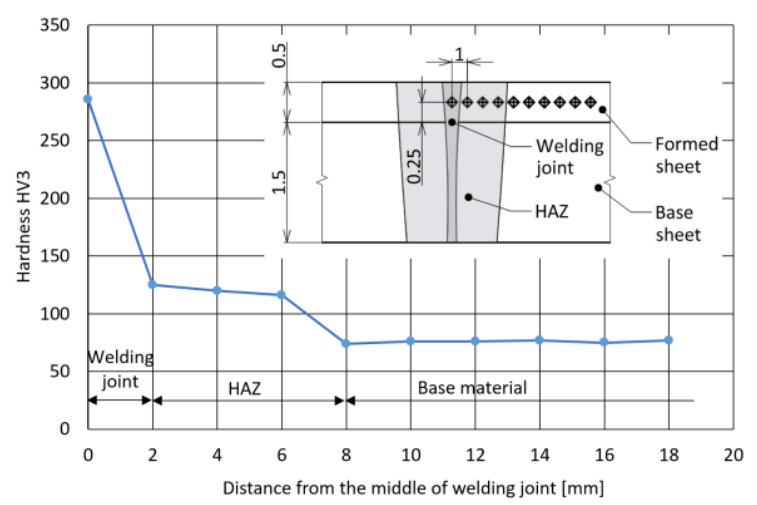

Figure 22: Hardness distribution

Fig. 22 also demonstrates hardness dependence on the distance from the middle of the welding joint. It is observable that there are three zones: weld metal, heat affected zone and unaffected (base) material. The maximum value of $296 \mathrm{HV}$ was measured in the middle of the welding joint and from this point hardness decreases with the distance. The alternations in material properties are significant and it is clear that the heat affected material is shaped during the forming process. Thus, the calculated results show differences along the peripheral parts. Nevertheless, the numerical simulation is relevant for analysis of the critical areas of the part.

\section{GEOMETRY OPTIMIZATION}

The hydroforming technology options are limited by the critical areas of the part. However, change of the geometry can cause more appropriate stress distribution. Since the critical area is localized in the triangle element, the radius is selected as the parameter of optimization (Fig. 23).

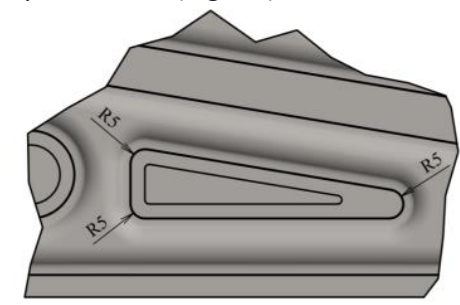

Figure 23: Optimized radius

The influence of the geometry change is observed for radius of 7 and $9 \mathrm{~mm}$. The properties of the numerical simulations for optimization are the same as for the original simulation except for the forming pressure (higher final values are set).

The results of the simulations show influence of the radius size on the critical forming pressure (Fig. 24). The trend of the curve is increasing and, as a result, the higher forming pressure can be used. This is important to reduce springback and achieve higher depth of punch.

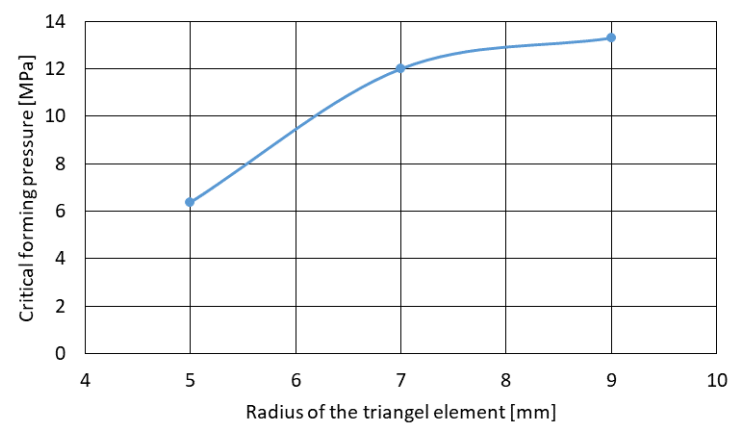

Figure 24: Influence of the optimized radius on the critical forming pressure

\section{CONCLUSIONS}

The analysed sandwich panel is used in solar panels as a reinforcement. For the manufacturing of the part was chosen the parallel hydroforming technology, which can cause excessive thinning and part cracking. The analysis of the defects was performed by the software PAM-STAMP. Subsequently, the results were compared to the real hydroforming process data. The first criterion was the failure pressure. The experimental value of 8.6 MPa was compared to the calculated value of 6.36 $\mathrm{MPa}$, which is a percentage change of $26 \%$. The second criterion was material thinning. This comparison showed a maximum percentage change of $10.7 \%$ between the experimental and calculated data. The differences were apparently influenced by the welding process, the effect of which was not included in the numerical simulation conditions. This theory has been confirmed by the Vickers hardness test. Another cause of the result differences could be the fact that the compared measuring data are from one part only. There are several ways to increase the accuracy of the results. One of them is the creation of a numerical simulation of the welding process and application of its results.

The numerical simulation results were used for the geometry optimization of the critical area. This procedure leads to the possibility of using higher forming pressure, which in turn has positive effect on the process parameters such as a springback and a depth of the punch.

\section{ACKNOWLEDGEMENTS}

This paper was supported by project "Analysis of formability and weldability of materials produced by 3D wire metal printing" no. FSI-S-20-6336 within the specific research of Faculty of Mechanical Engineering, Brno University of Technology.

\section{REFERENCES}

[Altan 2012] Altan, Taylan and A. Erman Tekkaya. Sheet metal forming: processes and applications. Materials Park, Ohio: ASM International, 2012, ISBN 978-1-61503-844-2

[Banabic 2010] Banabic, Dorel. Sheet metal forming processes: Constitutive modelling and numerical simulation. New York: Springer, 2010, ISBN 978-3-540-88112-4

[Buchar 2000] Buchar, Jaroslav, et al. Evaluation of constitutive relations for high strain rate behaviour using the Taylor test. Le Journal de Physique IV. 2000, pp Pr9-75 - Pr9-80, ISSN 1155-4339

[Campbell 2010] Campbell, Flake C. Structural composite materials. Materials Park, Ohio: ASM International, 2010. ISBN 978-1-61503-037-8

[Harant 2019] Harant, Martin. Manufacturing of a component by using hydroforming technology and its optimization. Brno: Brno University of Technology, 2020

[Hein 1999] Hein, Philipp and Frank Vollertsen. Hydroforming of sheet metal pairs. Journal of Materials Processing Technology. 1999, pp 154-164, ISSN 0924-0136

[Liu 2012] Liu, Wei, et al. Welded double sheet hydroforming of complex hollow component. Transactions of Nonferrous Metals Society of China. 2012, Vol.22, pp 309-314, ISSN 1003-6326 


\section{CONTACT}

Ing. Martin Harant, Ing. Jan Rihacek Ph.D.

Brno University of Technology, Faculty of Mechanical Engineering,

Institute of Manufacturing Technology, Department of Metal Forming

Technicka 2896/2, Brno, 616 69, Czech Republic

e-mail: 170977@vutbr.cz

e-mail: rihacek.j@fme.vutbr.cz

doc. RNDr. Libor Mrna Ph.D.

Brno University of Technology, Faculty of Mechanical Engineering,

Institute of Manufacturing Technology, Department of Metal Forming

Technicka 2896/2, Brno, 616 69, Czech Republic

Institute of Scientific Instruments of the Czech Academy of Sciences, Brno, Czech Republic

Kralovopolska 147, Brno, 612 00, Czech Republic

e-mail:mrna@fme.vutbr.cz,mrna@isibrno.cz 